\title{
Salud mental y ética: El concepto de sentimiento de comunidad en la psicología de Alfred Adler
}

\author{
Úrsula Oberst \\ Universidad Ramón Llull \\ Barcelona, España
}

En este estudio se define el concepto adleriano de sentimiento de comunidady sus implicancias éticas intentando equipararlo con el de salud mental. Se revisan los inicios de la psicología individual y las principales diferencias con el psicoanálisis ortodoxo para conducir a la visión humanista y social que Adler tiene de la persona y su problemática psicológica, así como a la afirmación de que el sentido de la comunidad constituye un marco ético para una adecuada valoración de la actividad humana. Se revisan, además, los conceptos básicos de la psicología adleriana con la finalidad de definir la salud mental como la intensidad de sentimiento de la comunidad que posee una persona, considerado por Adler como un punto de referencia y no como una verdad absoluta. El sentimiento de comunidad es algo a lo que se debe aspirar "como si" (Als ob) fuera alcanzable.

psicología individual / salud mental / sentimiento de comunidad

\section{Mental health and ethics: The concept of "sense of community" in Alfred Adler's psychology}

This study defines Adler's concept of "sense of community" and its ethical consequences equating it to mental health. The beginnings of individual psychology and the differences with orthodox psychoanalysis are analyzed to lead to the humanistic and social vision Adler has of persons and their psychological complexity. For Adler the sense of community constitutes the ethical framework that provides value to human activity. Basic concepts of Adler's psychology are further discussed in order to define mental health as the intensity of the sense of community that a person has, which becomes a reference point and not an absolute truth. The sense of community is something one should aspire "as if" (Als ob) it were realizable.

individual psychology / mental health / sense of community

Dirección de la autora: ursulao@blanquerna.url.es 


\section{INTRODUCCIÓN}

Alfred Adler (1870-1937), el fundador de la psicología individual (o psicología adleriana), es poco conocido en España $\mathrm{y}$, muchas veces, sólo como disidente del psicoanálisis clásico de Freud. Generalmente se considera la psicología individual como una de las tres psicologías "profundas" junto con Freud y Jung; pero, en muchas publicaciones aparece también como precursor de enfoques más recientes, como la psicología humanista (Mosak, 1989; Dreyfus \& Nikelly, 1979) o el constructivismo (Mahoney, 1991; Scott et al., 1995). Adler empezó su trabajo como psicoterapeuta en 1902, en el seno del psicoanálisis, como colaborador de Freud, pero se desmarcó pronto de éste al disentir de muchas ideas freudianas, como, por ejemplo, de la noción del origen sexual de la neurosis o la de que siempre tiene que haber un trauma en la infancia, una experiencia o impulso reprimido que acaba en trastorno psicológico (Adler, 1911/1973). A lo largo del desarrollo de sus propias ideas, Adler se movía hacia una visión más humanista y constructivista y, a la vez, más social de la persona y de sus problemas psicológicos: por un lado, Adler concibe al ser humano de forma holística, como una unidad y no dividido en instancias o en consciente y subconsciente como lo hacía Freud -de ahí la denominación psicología individual (de in-dividuus), y por otro lado lo contempla siempre dentro de y respecto a su entorno: las emociones, actitudes, acciones y pensamientos no se evalúan desde la persona misma, sino siempre en su contexto social: la comunidad (Gemeinschaft). Como consecuencia, la salud mental (igual que su polo opuesto, el trastorno psicológico) también se evalúa desde un punto de vista de la comunidad y, para Adler, el criterio de salud mental se define por el grado de sentimiento de comunidad (Gemeinschaftsgefühl) que posee el individuo. El presente artículo intenta dilucidar este concepto adleriano del sentimiento de comunidad y sus implicaciones éticas.

\section{CONCEPTOS BÁSICOS DE LA PSICOLOGÍA ADLERIANA}

\section{Ficcionalismo y finalidad}

Como se ha destacado antes, la visión adleriana de la personalidad se solapa en muchos aspectos con visiones humanistas y constructivistas. Adler concibe a la persona como in-dividuo que posee una personalidad única integradora (el estilo de vida, Lebensstil). La persona está guiada, sobre todo, por objetivos y metas que intenta alcanzar, aunque no siempre es plenamente consciente de ellos. Para entender a una persona no hace falta tanto entender las causas de su conducta, sino más bien sus objetivos. Estos objetivos suelen ser ficticios.

Adler adapta la noción de ficción de la obra del filósofo alemán Hans Vaihinger quien, con su Philosophie des Als $\mathrm{Ob}$ de 1911, fundamentó una forma alemana del pragmatismo. Las ficciones son, según Vaihinger (1911/1965), ideas y creaciones psíquicas del individuo que no tienen una correspondencia en la rea- 
lidad, pero que cumplen una función sumamente útil al capacitarlo para tratar mejor con su entorno. Se suelen citar como ejemplo los meridianos geográficos que no existen en la realidad, pero que tienen una gran utilidad en la vida diaria. Una ficción se puede tomar como fundamento y como línea directriz para las actuaciones, aunque su verdad sea dudosa: podemos actuar "como si" en la tierra existiesen los meridianos y como si nuestras construcciones idiosincrásicas de la realidad fuesen verdad. Aunque no haya correspondencia con la realidad, Vaihinger, como pragmatista, distingue ficciones más o menos útiles, en el sentido de validez para orientarnos en el mundo. Para Vaihinger, este mundo del "como si", este mundo irreal, es tan importante como el mundo llamado real, y quizás más importante en los ámbitos de ética y estética. En este sentido, la "verdad" no existe: según Vaihinger (y Adler adopta esta idea), lo que llamamos verdad sólo es la ficción más útil o el grado más pragmático del error, y el error el grado menos pragmático de la ficción.

Adler lleva esta idea de las ficciones al ámbito de la psicología humana: el ser humano se construye ficciones, maneras idiosincráticas de percibir a sí mismo y al mundo, que le son necesarias para orientarse en su entorno, para guiar sus sentimientos y actitudes, para planificar y llevar a cabo sus actos. Pero sus ficciones pueden ser mejores o peores, más o menos útiles (o adaptativas, como diríamos hoy). Adler distingue entre ficciones en las cuales el error es grande y ficciones donde éste es pequeño: "Grandes errores pueden provocar neurosis; pequeños, en cambio, una personalidad casi normal." (Adler, citado en Ansbacher \& Ansbacher, 1975, 97).

El concepto de ficción está muy relacionado con el de la finalidad, la noción de que la persona persigue objetivos, metas y fines. Con este concepto de finalidad, Adler rechaza el determinismo en psicología a favor de una visión teleológica, de la causa finalis, hecho que llevó a algunos autores (por ejemplo Titze, 1983) a intentar cambiar la denominación de psicología individual por la de "teleoanálisis".

Respecto a la finalidad, Adler también distingue entre fines más o menos "útiles". Pero según Adler, un determinado objetivo sólo es útil cuando contribuye al bien de la comunidad, y no cuando es útil exclusivamente para la mayor gloria del individuo. Con esto, Adler se aleja de la idea puramente pragmatista de las ficciones al imponer un criterio ético a la finalidad de la persona. En este sentido, para un determinado individuo puede ser útil el instrumentalizar a otro por el bien de uno mismo, pero nunca desde el punto de vista de la comunidad. Pero Adler no se limita a aplicar este principio a la convivencia de personas normales, sino impone este criterio ético incluso a su concepción de la neurosis, como veremos más adelante. 
El concepto de finalidad explica la divergencia entre actitudes conscientes e inconscientes. La noción adleriana del inconsciente es bastante diferente de la de Freud. Adler afirma que el ser humano hace lo que (inconscientemente) quiere. Un cleptómano, por ejemplo, sabe y acepta moralmente que no hay que robar, pero de vez en cuando tiene la necesidad de hacerlo, sin entender por qué. Según Adler, esta persona obedece a una finalidad inconsciente que se puede descubrir en una psicoterapia y que puede ser de índole muy diversa (por ejemplo la necesidad de llamar la atención de sus padres, el deseo de vengarse de ellos, etc.). De la misma manera se explican otras formas de neurosis: el agorafóbico, que no puede salir de su casa, inconscientemente no quiere acudir al trabajo (por ejemplo), aunque conscientemente lo desee. La mujer que con sus graves y dolorosos ataques de migraña obliga a su marido a quedarse en casa con ella, tiene como objetivo precisamente eso: tener a su marido a su lado, aunque conscientemente lamente que éste no pueda ir al trabajo. La muchacha histérica, que produce síntomas de conversión poco antes de contraer matrimonio, inconscientemente no quiere casarse, aunque conscientemente sí ${ }^{1}$. La obtención de los fines persegui-

1 Estos ejemplos están sacados de casos de la época de Adler. Como destaca Sperber (1983), los trastornos psíquicos están sujetos a "modas" de una determinada sociedad. Síntomas de conversión dos mediante los síntomas neuróticos puede ser de gran importancia, hasta vital para el individuo (la mujer con migraña quizás teme -con razón o sin ella- perder al marido y tiene así un instrumento poderoso para obligarlo a permanecer a su lado; el niño que roba quizá se siente desatendido por sus padres y cree tener como último recurso el de atraer la atención de éstos mediante actos delictivos); sin embargo, estos objetivos (inconscientes) son, aunque comprensibles - desde la situación subjetiva del individuo-, inaceptables desde el punto de vista de la comunidad.

\section{Sentimiento de inferioridad y afán de poder}

Adler asume un patrón común entre estas ficciones "inútiles". Según él, cualquier neurótico tiene como ficción directriz el afán de superioridad o de poder (Machtstreben), entendido como sobrecompensación de un profundo sentimiento de inferioridad (Minderwertigkeitsgefühl). En el fondo, el neurótico es una persona que se siente pro-

(histeria), en tiempos de Freud y Adler típicos de mujeres de la burguesía, ahora se dan muy raramente. De la misma manera, a la esposa de un obrero no se le "ocurriría" producir síntomas que obliguen a su marido a quedarse en casa con ella, ya que éste, por muy mal que le sepa, no se lo podría permitir. Esta observación de Sperber subraya que cada paciente produce -aunque inconscientemente- precisamente esta clase de síntomas que parecen más eficaces para conseguir un determinado objetivo. 
fundamente inferior a los demás, $\mathrm{y}$ cuanto más grande es su sentimiento de inferioridad, más imperiosa y fuerte se hace la necesidad de compensarlo con aires de superioridad, sentimientos de grandeza, y ardides psicológicos para mitigar esta sensación insoportable de ser insignificante o no valer nada. En las personas psíquicamente sanas, las ficciones mantienen un carácter predominantemente útil, podrá salir desde el punto de vista de la comunidad, mientras en las personas con disposición neurótica, las ficciones giran siempre en torno a una particular manera de sobrecompensar una supuesta inferioridad. La inferioridad es siempre ficticia, subjetiva y sujeta a la percepción idiosincrásica de la persona, ya que, para Adler, una inferioridad real de una persona no puede existir. En su visión, los seres humanos son, aunque no iguales, equivalentes, y por supuesto de igual valor (gleichwertig).

El sentimiento de inferioridad es, por lo tanto, una ficción que se forma, como generalmente todas las ficciones según Adler, en la primera infancia como respuesta activa del niño a su entorno y a sus experiencias. Pero, en ningún caso una determinada postura adoptada se puede reducir a condiciones y causas objetivas.

Sin embargo, existen condiciones que favorecen en el niño la percepción de su inferioridad; Adler distingue tres factores desfavorables (Adler, 1931/
1981): niños delicados de salud y con "minusvalía de órganos" (Organminderwertigkeit; hoy en día se diría disminución física, psíquica o sensorial), niños descuidados (vernachlässigt) o educados con excesivo rigor, y niños excesivamente mimados o consentidos (verwöhnt). Todos estos niños tienen un riesgo elevado de desarrollar sentimientos de inferioridad: el discapacitado o enclenque por su condición física más débil; el niño descuidado por falta de atención paterna o materna o por sufrir un exceso de trato autoritario que le impide sentirse perteneciente a la comunidad como miembro apreciado y equivalente (la familia como primera comunidad). Pero también el niño consentido, a quien sus padres siempre han protegido de manera excesiva de todos los pequeños obstáculos y dificultades de la vida, es un posible candidato al sentimiento de inferioridad, porque nunca ha aprendido a valerse por sí mismo o a aplazar sus deseos y necesidades o incluso a luchar por ellas.

No es amor lo que recibe el niño consentido, sino exclusivamente las ventajas de una existencia parasitaria, y esto le puede llevar a la convicción peligrosa de que siempre tiene que haber esclavos que le allanen el camino (Sperber, 1983). De esta manera, estos niños nunca experimentan el efecto estimulante de obstáculos superados y nunca aprenden a concordar sus deseos con las exigencias de la comunidad. 
Aunque estos tres factores mencionados constituyen, para Adler, un riesgo de producir sentimientos de inferioridad, no son condiciones que determinan al individuo. Lo más importante, para Adler es la toma de postura (Stellungnahme), la opinión o la actitud que se forma el niño activamente respecto a estas circunstancias. Es consabido que dos niños criados en las mismas condiciones desfavorables no desarrollan necesariamente las mismas condiciones psíquicas.

Según Adler, todos los seres humanos aspiran a un ideal utópico de última perfección (Adler, 1931/1981). Esta ficción directriz es el motor principal del hombre que le guía para salir de su condición biológica inferior (respecto a los demás seres vivos) y llegar a un máximo nivel de autoactualización, para utilizar un concepto más moderno. Adler considera que la naturaleza humana aspira a superar los obstáculos, alcanzar los fines propuestos, sentirse completo, fuerte y válido; y cada niño pequeño tiene que pasar por este proceso nuevamente. Este proceso adaptativo y autoactualizador del ser humano es posible por el afán de superación (no confundir con afán de superioridad, que es, como hemos visto, la sobrecompensación neurótica de un sentimiento de inferioridad subjetivo). En condiciones normales de la vida, el individuo, el niño en este caso, suele tener suficiente valentía (Mut) para enfrentarse con las dificultades cotidia- nas. Pero pueden existir condiciones, en las que el niño no tiene este valor (como hemos dicho, en el caso de existir una "minusvalía orgánica", o de ser un niño excesivamente mimado o descuidado); sin embargo, la necesidad de superar los obstáculos persiste. Un niño, por ejemplo, que siempre se ve expuesto a una situación donde los adultos se aprovechan de su condición superior (física o psicológica) tiene más riesgo de no llegar a formar una autoimagen positiva, asertiva. El camino directo hacia "arriba" le queda cerrado. Esto tiene un efecto altamente desalentador para el niño. Como consecuencia, tiene que probar otros caminos más indirectos, más torcidos, más complicados, que por rodeo lleguen igualmente al destino anhelado de superación. Así, un niño puede aprender que mediante lloros y berrinches o con síntomas psicopatológicos, como la enuresis, puede conseguir una atención muy superior a la que pudo conseguir con su conducta más directa. Vía ensayo y error, dependiendo de las reacciones de los adultos, el niño aprende a re-finalizar su debilidad, de manera que ahora le sirve para poner a los padres a su servicio y para ejercer poder indirecto. "El niño desanimado, que descubre que puede tiranizar más eficazmente su entorno mediante lágrimas, se convierte en un 1lorón; y del llorón al melancólico adulto hay un camino directo" (Adler, 1931/ 1981, 51). Para evitar malentendidos hay que añadir que Adler no niega el 
hecho de que el llanto del bebé sea vital para su supervivencia. Pero si el niño descubre que con el llanto puede hacer venir a los padres hasta cuando no necesita nada, experimenta una peligrosa sensación de poder sobre ellos.

Por esto, Adler siempre ha destacado la necesidad de mejorar las condiciones educativas. En sus últimas obras insiste constantemente en la necesidad de enseñar a padres y a maestros para educar mejor. Este conocimiento de que una buena educación puede evitar muchos males, psicopatología y delincuencia, llevó a Adler a aspirar a una máxima divulgación de sus ideas, no tanto en ámbitos profesionales sino entre la población en general. Sus últimas obras, por tanto, son de carácter divulgativo, escrito en un lenguaje y vocabulario más popular; en ellas, Adler diserta no tanto de aspectos psicopatológicos sino sobre cuestiones psicológicas más cotidianas y la convivencia humana en general, como el matrimonio, la educación de los niños, o la infravaloración de la mujer en la sociedad. Además, llegó a fundar en la ciudad de Viena cerca de treinta centros de educación infantil para niños difíciles que posteriormente, con la llegada del nazismo, fueron cerrados (Rattner, 1972). En estos centros-escuelas Adler intentaba promover lo que llamaba "educación democrática", en contraposición a una educación autoritaria (frecuente en su época) y a una educación laissez-faire (quizás predominante en nuestros tiempos). Esta educación democrática se basa en el respeto mutuo y pretende aceptar al niño como ser humano con la misma dignidad que un adulto, proporcionándole una educación hacia el sentimiento de comunidad, sin humillar al niño mediante trato autoritario ni consentirle todos sus caprichos. Este aspecto psicopedagógico de la psicología adleriana, en el ámbito familiar y escolar, ha sido elaborado posteriormente con más detalle en Estados Unidos por su discípulo más importante, Rudolf Dreikurs (por ejemplo Dreikurs, 1968; Dreikurs \& Soltz, 1964; Dreikurs, Grunwald \& Pepper, 1982).

\section{El sentimiento de comunidad}

Como hemos dicho arriba, Adler se niega a considerar a un individuo por sí solo, lo contempla siempre en contexto con sus congéneres. Para Adler, la psicología individual (y aquí queda patente cómo el término "individual" induce a error) "... es probablemente la teoría más consecuente de la opinión del individuo respecto a cuestiones de la vida social, y por eso una psicología social" (Adler, citado en Ansbacher \& Ansbacher, 1975, 134). El individuo, a pesar de ser en sí mismo una totalidad, sólo se puede contemplar en el conjunto de una totalidad mayor, la comunidad humana. Se puede decir que sólo en la comunidad, en relación con los demás, el individuo se convierte en persona. $\mathrm{Y}$, para entender lo que le pasa al Yo, hay que examinar sus relaciones con sus 
respectivos Tus. De esta manera, un síntoma psicopatológico como cualquier otra conducta no se entiende tampoco como algo intrapsíquico, sino como un aspecto de la vida de esta persona respecto de otras.

En la concepción adleriana, la comunidad constituye el marco ético para la valoración de un acto humano. La comunidad establece normas y exigencias que sirven de referencia para el individuo, pero a la par es el conjunto de los individuos que forman y revisan constantemente este marco normativo. Si a una persona se le llama buena o mala, sana o enferma, no se puede determinar desde un punto de vista absoluto, sino siempre desde el marco social. Al formar parte de esta comunidad, la persona se enfrenta a tres "tareas de la vida" como representantes de las exigencias de la comunidad que tiene que resolver satisfactoriamente: trabajo, amor y vida en comunidad (Adler, 1931/1981). Dreikurs (1969) añade dos tareas más: la relación del individuo consigo mismo y su relación con el universo, es decir con el significado de la existencia humana en el ámbito espiritual y trascendental.

Para poder vivir en comunidad, Adler postula una fuerza innata latente en el hombre, el sentimiento de comunidad, que se tiene que despertar y desarrollar en la infancia mediante la interacción con las demás personas (en primer lugar con la madre). Cuantas más posibilidades tiene el niño de hacer experien- cias positivas, "alentadoras" en el lenguaje de Adler, más probabilidades tiene de desarrollar un alto grado de sentimiento de comunidad. El niño, según Adler, nace con un potencial intrínsicamente bueno. Aquí es interesante la comparación con la visión de Freud, de un niño genuinamente egoísta con pulsiones destructivas que durante la socialización se tienen que reprimir. Para Freud, las normas y prohibiciones de la cultura pueden provocar los trastornos del individuo adulto al obligarle a reprimir sus instintos animales y egoístas y a trabajar por su sublimación. En la visión freudiana, la neurosis es el precio que pagamos para la civilización, mientras en la de Adler, el caso es el contrario: la neurosis es el precio que pagamos por nuestra falta de civilización.

Adler utiliza conscientemente la expresión sentimiento de comunidad, ya que es un concepto que se refiere principalmente a un aspecto psicológico, algo que la persona tiene que sentir. Cometer actos "buenos" sin la actitud "buena" correspondiente no tiene sentido, ya que el mero acto bueno sin la intención de contribuir al bien común, tendría la finalidad opuesta, la de realzar la propia autoestima en detrimento de los demás (afán de superioridad). Adler nunca da una definición clara de lo que entiende por sentimiento de comunidad, y es muy probable que no se pueda dar nunca ya que no se puede determinar en valores absolutos. Una 
aproximación a este concepto que subraya su aspecto de empatía sería el consejo de Adler de "ver con los ojos de otro, oír con los oídos de otro y sentir con el corazón de otro" (Adler, citado en Ansbacher \& Ansbacher, 1975, 142). La mayoría de los autores adlerianos está de acuerdo en que no significa sacrificarse por los demás en un altruismo malentendido (ya que sería una infravaloración de uno mismo) sino buscar el bien de uno mismo dentro del bien común. Para que esto sea posible, es preciso sentirse igual, de igual valor humano que los demás. Dreikurs (1969) afirma que sólo cuando nos sentimos iguales podemos estar seguros de nuestro sitio dentro de la comunidad, y desarrollar el sentimiento de pertenencia, base del sentimiento de comunidad. Para este autor, la capacidad de cooperación puede servir como medida del sentimiento de comunidad que uno posee. Para saber en qué medida una determinada conducta es expresión de sentimiento de comunidad, hay que evaluar en qué medida la persona tiene en cuenta las necesidades de una situación concreta, en qué medida es capaz de actuar "orientado a la tarea" (sachlich, task-oriented) sin preocuparse por su propio prestigio o por quedar bien.

Adler deja claro que este sentimiento de comunidad, aunque difícil de definir y sujeto a cambios a lo largo del desarrollo humano, es universal, es decir, nadie puede eludirlo. Es la "lógica férrea de la convivencia" (Adler, 1927/
1981). El que no se adapta, será neurótico, maladaptado o incluso delincuente (siempre desde el punto de vista de la comunidad en cuestión). No existe manera alguna de evitar estar sujeto a los dictados de la comunidad y sus exigencias. Aunque se intente negar estas condiciones, el sentimiento de comunidad prevalecerá en forma de conciencia, escrúpulos y remordimientos. Adler reconoce que, evidentemente, no siempre las personas actuan conforme al sentimiento de comunidad, pero siempre se necesita, según él, un cierto esfuerzo para negar esa voz de conciencia, y eso significa tener que buscar, al menos de cara a uno mismo, excusas o "atenuantes" para justificar un acto que no está conforme con el sentimiento de comunidad.

En el caso de un delincuente queda, en primer lugar, la búsqueda de atenuantes: excusas, subterfugios y coartadas que se refieren a su infancia dificil, a su condición social precaria, a la crueldad de la sociedad, etc. Como Adler niega el determinismo, no acepta estas excusas -por muy bien que se pueda comprender al delicuente a un nivel psicológico. La infancia difícil y la impasibilidad del entorno pueden hacer comprender la conducta, pero nunca la justifican. Adler no condena al delincuente, pero no le exculpa de sus actos contra la humanidad.

El caso de la persona neurótica es muy similar. Sus trastornos, sean los que fueren, derivan de una falta de sentimiento 
de comunidad. Adler (1933/1980) describe la actitud típica del neurótico como un "sí-pero". El "sí" expresa que el individuo es consciente de lo que dictan las exigencias de la comunidad, de lo que habría que hacer (“debería..."), mientras que el "pero" expresa la excusa que alega por no cumplir con ellas. Esta excusa está representada en el síntoma psicopatológico que tiene y puede ser muy variada, según las ficciones particulares del individuo (“... pero no puedo, porque... tengo ataques de ansiedad", por ejemplo). Este "pero", la excusa expresada por el síntoma, no es algo consciente. Si lo fuera, el paciente sería un simulador; además la función de autoengaño del síntoma (“... en el fondo tengo las mejores intenciones, pero mi trastorno me lo impide") no se podría cumplir con tanta eficacia. Debemos tener en cuenta esta naturaleza inconsciente del síntoma como excusa, ya que en algunas descripciones de sus casos a veces se obtiene la impresión de que Adler considera la neurosis como un vicio o una falta de fondo moral, y no es así.

Así que, para salvar la autoestima y la imagen de sí mismo como persona con las mejores intenciones, el "pero" se disfraza de un arreglo neurótico, un juego de autoengaño en la penumbra de la consciencia: "Sí, quiero ser un gran profesional, pero siempre tengo estos ataques de ansiedad cuando tengo que pasar un examen." O: "si no tuviera estos ataques de ansiedad, sería un alum- no brillante". En vez de luchar en el terreno de los logros académicos dónde este alumno no puede o cree que no puede superarse, libra escaramuzas fuera de donde se desarrolla la batalla principal (Adler, aunque pacifista declarado, se expresaba muchas veces en un lenguaje militar), y donde al menos se asegura la superioridad mediante la consideración, la conmiseración y quizás hasta los cuidados que le brindan los demás a causa de su estado lamentable que le impide tener éxito en la vida. El síntoma es utilizado como coartada, y el sufrimiento causado por él es el precio ("costes de guerra") que el individuo paga por salvar la cara.

No cabe duda de que el neurótico sufre, pero siempre prefiere estos sufrimientos a otros más grandes, es decir al hecho de parecer inútil a la hora de solucionar sus problemas. Prefiere la aceptación de todos los trastornos neuróticos al descubrimiento de su futilidad. Insistirá: 'Sí, quiero ponerme bien, quiero quedar libre de los síntomas'. Por eso va al médico. Pero lo que no sabe es que hay algo que teme aún más: que salga su poca importancia; podría revelarse que no vale nada. Ahora vemos lo que es la neurosis en el fondo: un intento de evitar el mal mayor, un intento de mantener la apariencia de valor a todo precio, pagar todos los gastos, pero desear a la vez conseguir el objetivo sin pagarlos. (Adler, 1933/1980, 108-109).

En cambio, si la persona tuviera más sentimiento de comunidad, dejaría de luchar por la autoexaltación mediante la búsqueda del reconocimiento fácil por parte de los demás y, en el caso del pa- 
ciente arriba mencionado, dedicaría sus esfuerzos a los estudios, o, si le falta capacidad intelectual suficiente, a otro trabajo satisfactorio. Adler resume:

Todos los fracasados -neuróticos, psicóticos, criminales, alcohólicos, niños difíciles de educar, suicidas, perversos y prostitutas- lo son, porque les falta sentimiento de comunidad. Se enfrentan a los problemas del trabajo, de la amistad y del amor sin la confianza de que estos problemas se pueden resolver a través de la colaboración. La opinión que tienen de la vida es una opinión privada. Nadie excepto ellos mismos obtiene un beneficio de que logren sus propósitos, y su interés se limita a la propia persona. Su objetivo es tener éxito, ganar superioridad personal, y sus triunfos sólo tienen significado para ellos mismos (Adler, 1931/1981, 8).

Ya hemos destacado que a pesar de su lenguaje duro, Adler no condena a estas personas. El neurótico es "culpableinocente" a la vez (Adler, 1912/1977, 277), y Adler lo suele llamar "desanimado" (entmutigt), ya que la falta de valor está en la base de todo. Los devaneos, trucos y montajes del neurótico para escaparse de sus responsabilidades son, aunque "deliberados", inconscientes, y en la psicoterapia se intenta hacerle ver al paciente lo que hasta ahora no sabe conscientemente, porque hasta ahora, por falta de valor, ha cerrado los ojos ante las consecuencias y no ha querido saber lo que con un psicoterapeuta comprensivo puede llegar a entender. El terapeuta adleriano, a la vez de descubrirle cautelosamente al paciente sus "síntomas-excusas", sobre todo intenta infundirle ánimos con técnicas de empatía y de "alentamiento" (Ermutigung, encoratjament en catalán) para vencer sus sentimientos de inferioridad que están en la base de sus problemas. Esto requiere una relación impregnada, asimismo, de sentimiento de comunidad, de respeto mutuo y de amistad. Sin estas condiciones y sin que el terapeuta aprecie profundamente al paciente (aunque rechace sus actos) y sin que el terapeuta crea en las posibilidades de crecer del paciente, el cambio terapéutico no es posible. Además, Adler siempre ha destacado que la aceptación de la terapia y de las propuestas del terapeuta por el paciente ha de ser libre y voluntaria: "Se puede llevar un caballo al agua, pero no hacerlo beber." (Adler, 1933/1980, 174).

Así, el cometido del terapeuta es fundamentalmente educativo: enseñar al paciente en un "ejercicio en cooperación" (Adler, citado en Dreifus y Nikelly, 1979) a desarrollar un sentimiento de comunidad. Pero esto significa que el terapeuta tenga, asimismo, un alto grado de este sentimiento de comunidad. Para posibilitar esto, la psicología adleriana obliga a los aspirantes a terapeutas a pasar por lo que se llama "análisis didáctico", es decir una terapia adleriana por otro acreditado terapeuta experimentado.

En la visión de Adler, la neurosis (el trastorno psicológico) es -igual que cualquier otra conducta no adaptada, como la delincuencia-, en el fondo, una 
falta de sentimiento de comunidad, es decir una forma de afán de superioridad como compensación de un sentimiento ("complejo") de inferioridad. Esta particularidad distingue la psicología adleriana de cualquier otro enfoque psicológico y psicoterapéutico, y por supuesto del psicoanálisis freudiano. Aunque se reconocen las influencias del entorno en la persona y no se pretende culpabilizar al paciente, sí se le considera responsable (precisamente porque también se le considera libre) y, sobre todo, no se le permite considerarse a sí mismo una víctima de sus circunstancias. Adler rechaza el determinismo (absoluto) de las circunstancias y concibe al ser humano como proactivo, dotado de libre albedrío y constituyente de su propio destino. Más importante que cualquier experiencia objetiva es la toma de postura (Stellungnahme), la elección de cómo interpretar esta experiencia. Y esta elección es libre. Sin embargo, Manés Sperber (1983), amigo y discípulo de Adler, aclara que después de cada elección las posibilidades de elegir se van restringiendo cada vez más, ya que la elección anterior condiciona y limita el número de las elecciones siguientes, debido a las reacciones del entorno. Estas reacciones de los demás pueden servir de correctivo para el individuo o confirmar una determinada percepción sesgada, de manera que su evaluación se distorsiona cada vez más, y el individuo llega a tener visiones del mundo más y más idiosincráticas.
El concepto de sentimiento de comunidad tiene un marcado acento utópico y ético. Estos puntos de vista adquieren suma importancia en las últimas publicaciones de Adler, son más maduras, completas y, a la vez, más fáciles de leer porque van dirigidas, como ya hemos dicho, a un público no exclusivamente profesional. Y siempre surge el tema del sentido de la vida. Sus dos últimos libros se titulan en castellano: $E l$ sentido de la vida (Adler, 1933) y Para qué vivimos (Adler, 1931). ¿Qué es para Adler el sentido de la vida? Una vida humana tiene sentido si es guiada por "el objetivo de conseguir el bien de toda la humanidad" (Adler, 1933/1980, 168), si aspira a un estado de "mayor capacidad de cooperación" (ibídem) y si "cada uno se presenta, más que antes, como parte de una totalidad" (ibídem). En otras palabras: la vida tiene sentido si la superación de las dificultades, incertidumbres, inclemencias y peligros de la vida no se busca a expensas de otros, en contra de otros o por encima de otros, sino junto con ellos y por el bien de todos (el propio incluido). Y si se aspira a la perfección no de la propia persona, sino a la perfección de la obra, por pequeña que sea. Un gran científico, un benefactor de la humanidad, para Adler, no tiene más valor que cualquier trabajador que hace bien su trabajo y que aspira a una convivencia bien llevada. Esta superación de la condición humana tiene un aspecto sub specie aeternitatis: 
Sentimiento de comunidad significa sobre todo una aspiración hacia una forma de comunidad considerada como eterna, como podría ser cuando la humanidad haya conseguido el objetivo de la perfección. No se trata nunca de una comunidad o sociedad en el presente, tampoco de formas políticas o religiosas; el objetivo más idóneo para la perfección tendría que ser un objetivo que significa la comunidad ideal de toda la humanidad, la última realización de la evolución (Adler, 1933/1980, 166).

Esta comunidad ideal y utópica (y por lo tanto inalcanzable) impregnada por el sentimiento de comunidad de las personas que la constituyen debe servir a las personas como guía de sus actos. La humanidad se aproximará a esta utopía cuando mayor cantidad de personas adquieran ese sentimiento de comunidad. Por lo tanto, es lógico que Adler pusiera tanto afán en la divulgación de sus ideas a un público lo más amplio posible. Pero es perfectamente consciente del carácter utópico de esta comunidad perfecta. Es más, la última realización de la perfección, tanto en el individuo como en la comunidad, sería Dios.

No sabemos cuál es el único camino cierto. La humanidad hizo diversos intentos de imaginarse este último fin del desarrollo humano. La mejor imagen que hasta ahora se ha hecho de este ascenso de la humanidad es la noción de Dios. No cabe duda de que la noción de Dios comprende en el fondo como meta aquel movimiento hacia la perfección que, como objetivo concreto de perfección, corresponde mejor al vago anhelo del hombre de conseguir la perfección (Adler, 1933/1980, 165).

Sin embargo, aspirar a un estado utópico de perfección de sentimiento de comunidad - por definición no alcanzablesería una ficción que, asimismo, no estaría de acuerdo con el sentimiento de comunidad, por no estar adaptada a la realidad. El gran problema del neurótico es, precisamente, su necesidad de ser siempre el mejor, el primero, el perfecto. Por eso, Adler anima a sus pacientes a tener también el valor de ser imperfecto, ya que la imperfección corresponde al ser humano y la perfección, aunque pueda servir como ficción de guía, sólo corresponde a Dios. Y si la psicología adleriana predicara el sentimiento de comunidad como el valor único y absoluto, el sentimiento de comunidad se convertiría en una ficción, es decir de una construcción pragmática orientadora en el sentido de Vaihinger, en un dogma. Por lo tanto, hay que ser siempre consciente del carácter utópico y ficticio de este objetivo: aspirar al sentimiento de comunidad y a la comunidad ideal sólo puede ser una ficción pragmática, un punto de referencia o una "hipótesis de trabajo" (Ansbacher \& Ansbacher, 1975), y hay que aspirar a ella sólo "como si” fuera alcanzable. Además, el significado del sentimiento de comunidad no se puede considerar como una verdad absoluta ya que puede variar de sociedad en sociedad y a lo largo de los tiempos; no es un valor eterno e inamovible; está sujeto a cambios y se forma y 
se modifica en la interacción social y mediante consenso social. Aunque en este aspecto de consenso social se pueden detectar paralelismos con el construccionismo social de Gergen (1996) y, en otros aspectos, también se puede considerar la psicología adleriana como constructivista (Scott et al., 1995), en esta idea utópica de una línea ética para guiar la humanidad hacia un estado mejor, Adler es claramente humanista y no constructivista.

El componente ético del sentimiento de comunidad viene dado también por su relación con aspectos religiosos. "Amarás al prójimo como a ti mismo" es un mandamiento (no sólo) del cristianismo y, básicamente, es lo que implica el sentimiento de comunidad. Adler, judío converso al protestantismo, también se ocupó de temas religiosos; por ejemplo, en una publicación conjunta con un teólogo protestante (Jahn \& Adler, 1933/1983) sobre cómo orientar a las personas y en qué medida la psicología individual se puede concebir como un forma de asistencia espiritual o pastoral profana. Aunque hay afirmaciones de adlerianos, como la de que "la psicología individual es una buena religión si eres tan desafortunado de no tener otra" (Rasey, citado en Mosak, 1989) y aunque Adler mismo llega a afirmar que la psicología individual puede servir de protectora del "sagrado bien de la humanidad allí donde la religión ha perdido su influencia" (Jahn \& Adler, 1933/1983), Adler siempre deja claro que la orientación pastoral corresponde a la religión y no a la psicología.

No obstante, la psicología individual puede poner a disposición de los clérigos sus conocimientos y técnicas para que éstos logren un mejor asesoramiento de los fieles respecto a problemas no exclusivamente espirituales, por ejemplo, de matrimonio o educación de los hijos. Con esta idea, Adler sienta las bases del counseling (orientación psicológica) llevado a cabo por sacerdotes especialmente formados, hoy en día práctica habitual en Estados Unidos y en otros países.

Aparte de esto, el afán humanista de Adler, el tono religioso de algunas afirmaciones y, sobre todo, la equiparación de salud mental con sentimiento de comunidad y, por lo tanto, con la ética, puede aterrar a muchos psicólogos y no psicólogos.

Aunque poca gente pusiera en duda de que el hecho de cuidar (también) de los demás puede contribuir a un bienestar psíquico personal, la recomendación supuestamente terapéutica de dejar de pensar en uno mismo y hacer cada día algo positivo para otra persona (como lo hizo una vez Adler con un paciente, según Sperber, 1983), es realmente algo inaudito en psicoterapia. Y es algo no siempre popular en una sociedad individualista y competitiva. 
CONCLUSIONES Y PERSPECTIVAS FUTURAS

En este breve artículo se ha intentado esbozar a grandes trazos los conceptos principales de la psicología de Alfred Adler, y subrayar el entrelazado de su idea de salud mental con valores sociales. Aunque no es un enfoque nuevo, considero que vale la pena continuar teniéndolo en cuenta hoy en día y precisamente en nuestra condición posmoderna con su ausencia de fundamentos, su fragmentariedad y su pérdida de la verdad como criterio absoluto. Estos aspectos provocan una creciente dificultad de elegir entre la inmensa cantidad de opciones y de adoptar una postura moral definitiva. Pero esta falta de criterio absoluto confiere al individuo la libertad (y la responsabilidad) de elegir sus propios valores éticos. Como destacan Botella y Figueras (1995):

Con la pérdida de los sistemas generales de legitimación, los grandes metarrelatos que justificaban y contenían en ellos mismos un poder legitimizante, universal y necesario, ya no justifican las acciones por un sistema mayor o por la idea del progreso. Así, se recupera el sujeto como último ser responsable de sus acciones morales, negándole la comodidad y seguridad que suponían un Bien y un Mal universales. Paradójicamente, el relativismo posmoderno conduce directamente a poner en primer plano la ética de la acción y del discurso (p. 20).
Desde este punto de vista, la psicología adleriana, con su ideal del sentimiento de comunidad puede representar una postura ética tentadora como respuesta a estas cuestiones éticas que suscita el pensamiento posmoderno. 


\section{REFERENCIAS}

Adler, A. (1911/1973). Zur Kritik der Freudschen Sexualtheorie des Seelenlebens. En: W. Metzger (Ed.), Heilen und Bilden.42-52. Frankfurt: Fischer.

Adler, A. (1912/1977). Über den nervösen Charakter. Frankfurt: Fischer.

Adler, A. (1927/1981). Menschenkenntnis. Frankfurt: Fischer.

Adler, A. (1931/1981). Wozu leben wir? Frankfurt: Fischer.

Adler, A. (1933/1980). Der Sinn des Lebens. Frankfurt: Fischer.

Ansbacher, H.L. \& Ansbacher, R.R. (1975). Alfred Adlers Individualpsychologie: Eine systematische Darstellung seiner Lehre in Auszügen aus seinen Schriften. München: Reinhardt.

Botella, L. \& Figueras, S. (1995). Cien años de psicoterapia: ¿El porvenir de una ilusión o un porvenir ilusorio? Revista de Psicoterapia, 4 (24), 13-28.

Dreikurs, R. (1968). Psychology in the classroom. New York: Harper \& Row.

Dreikurs, R. (1969). Grundlagen der Individualpsychologie. Stuttgart: Klett.

Dreikurs, R., Grunwald, B. \& Pepper, F.C. (1982). Maintaining sanity in the classroom. New York: Harper \& Row.

Dreikurs, R. \& Soltz, V. (1964). Children: the challenge. New York: Duell, Sloan \& Pearch.

Dreyfus, E.A. \& Nikelly, A.G. (1979). Existential-humanism in Adlerian Psychology. En: A.G. Nikelly (Ed.), Techniques for behavior change. Springfield, Il.: Charles C. Thomas.
Gergen, K.J. (1996). Realidades y relaciones. Barcelona: Paidós.

Jahn, E. \& Adler, A. (1933/1983). Religion und Individualpsychologie. Frankfurt: Fischer.

Mahoney, M. (1991). Human change processes. Delran, N.Y.: Basic.

Mosak, H. (1989). Adlerian Psychology. En: R.J. Corsini \& D. Wedding (Eds.), Current Psychotherapies. 65-116. Itaca, IL: Peacock.

Rattner, J. (1972). Alfred Adler. Reinbek: Rowohlt.

Scott, C.N., Kelly, F.D., \& Tolbert, B.L. (1995). Realism, constructivism, and the Individual Psychology of Alfred Adler. Individual Psychology, 51(1), 4-20.

Sperber, M. (1983). Alfred Adler oder das Elend der Psychologie. Frankfurt: Klett.

Titze, M. (1983). Fundamentos del teleoanálisis adleriano. Barcelona: Herder.

Vaihinger, H. (1911/1965). The philosophy of "as if". London: Routledge. 